RASĀYAN J. Chem.

Vol. 13 | No. 3 |1458-1471| July - September | 2020 ISSN: 0974-1496 | e-ISSN: 0976-0083 | CODEN: RJCABP

\title{
SYNTHESIS, CHARACTERIZATION AND STUDY OF FLUORESCENT-HIGH PERFORMANCE POLYESTERS
}

\author{
Jignasa V. Modh and Saurabh. K. Patel* \\ Department of Chemistry, Veer Narmad South Gujarat University, \\ Surat-395007(Gujarat) India. \\ *E-mail: saurabh.silvina@gmail.com
}

\begin{abstract}
Fluorescent-High performance polyesters have been synthesized by the polycondensation method at high temperature using cetrimide as initiator. Ten Polyesters were synthesized having different aliphatic-aromatic diols in the chain having s-triazine ring as the main moiety. Modification and introduction of the bulky pendent group in monomer structure increase the thermal stability of the polymers. The synthesized polymers have shown gray to black color. The solubility properties of synthesized polyesters were carried out in polar and non-polar solvents. The inherent and reduced viscosities were checked by Ubbelohde solution Viscometer and intrinsic viscosity was measured using Huggins and Kraemer's equations. Thermogravimetric analysis of all the polyesters has been carried out. The unique property of fluorescence of these polyesters makes them valuable candidates as high-performance materials.

Keywords: Polycondensation, Thermogravimetric Analysis, High Performance, Fluorescence, Viscosity.

(C) RASĀYAN. All rights reserved
\end{abstract}

\section{INTRODUCTION}

In recent years, many researchers have been affected by the synthesis and characterization of fluorescent high-performance polymers. ${ }^{1}$ High thermal stability of polymers due to the s-triazine moiety, it is notable that the s-triazine ring is heat resistant. ${ }^{2,3}$ Polymers having S-Triazine ring become a subject of interest because of good thermal stability, enhanced toughness and low moisture absorption and commercially available high-performance engineering plastic materials. ${ }^{4}$ The Triazine based material reveals outstanding high-temperature performance, which could be assigned to the $\mathrm{N}$ - heterocyclic structures ${ }^{5}$. Polymers containing the triazine ring as part of the polymer chain are usually insoluble and infusible. However, the thermal stability of the triazine ring makes it an attractive monomer for use in high-temperature polymers. High-performance polymers have been utilized in applications that demand services at elevated temperatures while maintaining their structural integrity and an outstanding combination of chemical, physical and mechanical properties.

Since the 1980s, fluorescent polymers utilized in commercial development further attracted tremendous scientific and industrial interest due to their potential in achieving the goal of light-emitting device technology that is economically viable for solid-state lighting and displays, which offer significant gains in power efficiency, color quality, and lifetime at a lower cost and less environmental impact than traditional incandescent and fluorescent lighting. ${ }^{6-14}$

Fluorescent polymeric materials have been achieved a great intentness owing to wide range application such as clean energy technologies ${ }^{15}$, explosive sensing, $\mathrm{pH} /$ temperature sensor, biological imaging ${ }^{16}$ life science, material science, ultrasensitive molecular diagnosis and novel light-emitting Nano devices ${ }^{17}$, and biological detection schemes, smart polymer machines, fluorescent chemosensor, fluorescent molecular thermometers, fluorescent imaging, drug delivery carriers, and so on. ${ }^{18,19}$ Fluorescent polymers can be developed with different methods, generally, there are two admittances for the preparation of fluorescent polymers. One of them polymerization of a monomer having a fluorescent chromophore such as fluorescent compounds as initiator, fluorescent compounds as chain transfer agents, chemical bonding between fluorescent groups and polymers ${ }^{20-24}$, the second is the chemical variation of polymers by fluorescent 
RASĀYAN J. Chem.

Vol. 13 | No. 3 |1458-1471| July - September | 2020

molecules or fluorescent oligomers The second one is chemical alteration of commercially available polymers having reactive groups by using fluorescent dyes or organic molecules. ${ }^{25,26}$

The present investigation aimed to synthesize new kinds of fluorescent polyesters bearing an outstanding combination of high-performance properties evolving owing to the attachment of s-triazine ring with coumarin ring.

\section{Material and Methods}

\section{EXPERIMENTAL}

Freshly prepared double distilled water was used for the preparation of solutions. Chemicals such as Sodium hydroxide pallets, Sodium bicarbonate, Thionyl chloride, Cetramide were used as received. The solvents carbon tetrachloride, chloroform, methanol, ethanol, acetone, benzene, n-butanol, ethyl acetate, amyl acetate, isoamyl acetate, dimethylformamide (DMF), dimethyl sulfoxide (DMSO) were received from Merck. Cyanuric chloride was purified recrystallization from pure benzene (m. p1460C). Bisphenol-A (Atul Ltd.) was repeatedly crystallized from 50\% aqueous acetic acid and finally purified by recrystallization from benzene (m.p. $150^{\circ} \mathrm{C}$ ). Bisphenol-S and Bisphenol-F (Atul Ltd.) were recrystallized from benzene (m.p. $187^{\circ} \mathrm{C}$ ). Neopentyl glycol, 1,4 Dihydroxy Naphthalene, 1,6 Haxene diol, 1,4 Butanediol, Resorcinol, Mono ethylene glycol, Diethylene glycol were received and purified by recrystallization from rectified spirit.

\section{Synthesis of 2-(7-Hydroxy 4-methyl coumarino)-4, 6-dichloro-s-triazine [CT] ${ }^{27}$}

A solution of cyanuric chloride $(18.44 \mathrm{~g}, 0.1 \mathrm{M})$ in a $60 \mathrm{ml}$ acetone was added with stirring to a cooled solution $\left(0-5^{\circ} \mathrm{C}\right)$ of sodium bicarbonate $(10.6 \mathrm{~g})$ in $100 \mathrm{ml}$ of distilled water, in a three-necked flask $(250 \mathrm{ml})$ equipped with a mechanical stirrer. This resulted in the formation of a slurry of cyanuric chloride. A solution of 7-hydroxy 4-methyl coumarin $(17.60,0.1 \mathrm{M})$ in $10 \mathrm{ml}$ of acetone was added to the cold slurry of cyanuric chloride. The mixture was stirred for 2 hours at $0-5^{\circ} \mathrm{C}$. The Off-white colored product was filtered, and recrystallized from ethanol and dried in vacuum desiccators. The yield was $78 \%$. M. P. $120^{\circ} \mathrm{C}$.

\section{Synthesis of 2-(7-Hydroxy-4-methyl coumarino)-4,6-bis- (N-Phenyl anthranilic acid) s-triazine $[\mathrm{CNT}]^{27}$}

A solution of 2-(7-hydroxy 4-methyl coumarino)-4, 6-dichloro-s-triazine (32.40g, $0.1 \mathrm{M})$ in $40 \mathrm{ml}$ of acetone was mixed with a solution of $\mathrm{NaOH}(16 \mathrm{~g}, 0.4 \mathrm{M})$ and $\mathrm{N}$ - phenyl anthranilic acid $(42.64 \mathrm{~g}, 0.2 \mathrm{M})$ in $80 \mathrm{ml}$ double distilled water. The reaction was stirred for $2 \mathrm{hr}$ at room temperature and $2 \mathrm{hr}$ at $80^{\circ} \mathrm{C}$. The separated solid was collected and washed with hot water. The product was dried in vacuum at $100^{\circ} \mathrm{C}$. The yield was $80 \%$. The product was recrystallized from acetone. M. P. $189^{\circ} \mathrm{C}$.

\section{Synthesis of 2-(7-Hydroxy-4-methyl coumarino)-4, 6-bis- (N-phenyl anthranyl chloride) s-triazine $[\mathrm{CNTC}]^{28}$}

Thionyl chloride (11.9ml, 0.1mol) was added into 2-(7-hydroxy-4-methyl coumarino)-4,6-bis- (N-Phenyl anthranilic acid) s-triazine [CNT] $(6.77 \mathrm{~g}, 0.1 \mathrm{M})$ in a dry round bottom flask. The reaction mixture was refluxed at $78^{\circ} \mathrm{C}$ for $2 \mathrm{hr}$. At the end of the reaction, excess thionyl chloride was distilled and the dry product was collected. The yield was about $82 \%$. The product was recrystallized from dimethylformamide. M. P. $267^{\circ} \mathrm{C}$.

\section{Synthesis of Polyesters ${ }^{29,} 30$}

2-(7-hydroxy-4-methyl coumarino)-4,6-bis- (N-Phenyl anthranyl chloride) s-triazine [CNTC] (0.01M) in the minimum quantity of DMF (approx. $10 \mathrm{ml}$ ) was stirred in a round bottom flask, then initiator cetrimide $(0.25 \mathrm{~g})$ was added and heated up to $150^{\circ} \mathrm{C}$. After adding diol $(0.02 \mathrm{M})$ the reaction temperature was raised to $160-180^{\circ} \mathrm{C}$ and heated for $7 \mathrm{hrs}$. The reaction mixture was cooled and poured with constant stirring in $250 \mathrm{ml}$ of ice-cooled water. Solid was filtered, washed with hot water and dried. Different types of polyesters were synthesized from 2-(7-hydroxy-4-methyl coumarino)-4,6-bis- (N-Phenyl anthranilic chloride) striazine [CNTC] and various diols using a similar method. NC-1 to NC-10 polyesters have been synthesized by using Bisphenol-A, Bisphenol-S, Bisphenol-F, Neo-pentylglycol, 1,4dihydroxy Naphthalene, 1,6 Haxene diol, 1,4 Butanediol, Resorcinol, Mono ethylene glycol, diethylene glycol, respectively. 
RASĀYAN J. Chem.

Vol. 13 | No. 3 |1458-1471| July - September | 2020

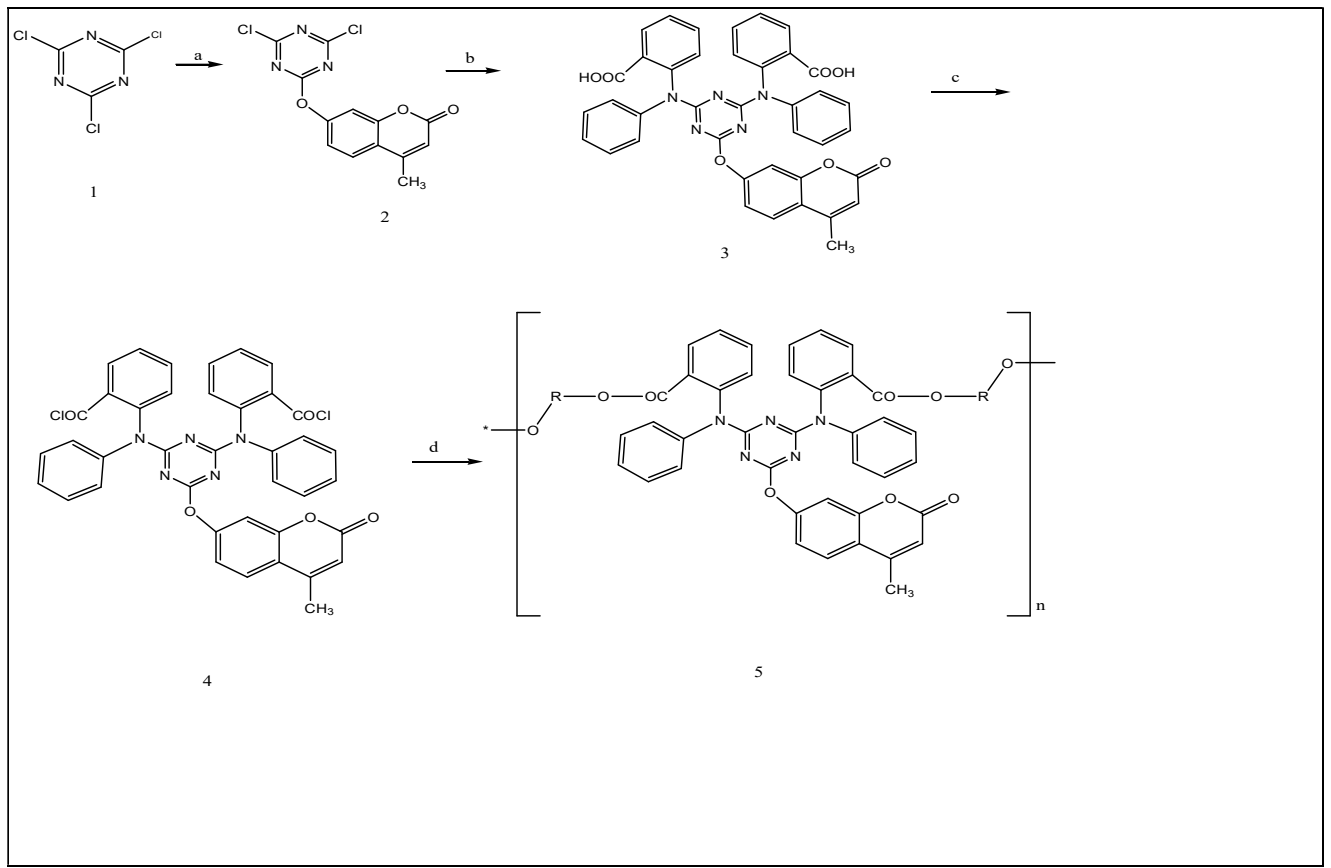

Scheme-1: Reagents: (a) 7-Hydroxy 4-methyl Coumarin in Acetone, 0-5 ${ }^{\circ} \mathrm{C}, 2 \mathrm{hr}$; (b) CT in 40ml of Acetone was mixed with a Solution of $\mathrm{NaOH}$ and $\mathrm{N}$ - Phenyl Anthranilic Acid in $80 \mathrm{ml}$ Double Distilled Water. (c) Add Thionyl Chloride in CNT and reflux it $2 \mathrm{hr}$ at $78^{\circ} \mathrm{C}$ (d) $\mathrm{HO}-\mathrm{R}-\mathrm{OH}$ in $\mathrm{DMF}$, Cetrimide, $8 \mathrm{hr}$ at $160-180^{\circ} \mathrm{C}$.

\section{Properties of Polyesters}

\section{RESULTS AND DISCUSSION}

Polyesters, which have been prepared from N-phenyl anthranilic acid, coumarin and different types of diols have unique colors. Most of the polyesters are gray to black (Table-1).

\begin{tabular}{c|c|c}
\multicolumn{3}{c}{ Table-1 } \\
\hline Polyester & Diol & Colour \\
\hline NC-1 & Bisphenol-A & Black \\
\hline NC-2 & Bisphenol-S & Black \\
\hline NC-3 & Bisphenol-F & Black \\
\hline NC-4 & Neopentyl glycol & Dark grey \\
\hline NC-5 & 1,4 Dihydroxyl naphthalene & Grey \\
\hline NC-6 & 1,6 Haxene diol & Dark grey \\
\hline NC-7 & 1,4 Butanediol & Black \\
\hline NC-8 & Resorcinol & Dark grey \\
\hline NC-9 & Mono ethylene glycol & Grey \\
\hline NC-10 & Di ethylene glycol & Grey \\
\hline
\end{tabular}

\section{Solubility}

Relative solubility of various polyesters synthesized from coumarin and N-phenyl anthranilic acid has been carried out in different solvents. It is shown that the solubility of the polyesters in different solvents reveals that polyesters are insoluble in aliphatic chlorinated solvents like chloroform, carbon tetrachloride. Polyesters are also insoluble in halogenated and Non- halogenated solvents such as chlorobenzene, benzene. Polyesters are partly soluble in acetone, methanol, ethanol, THF, n-butanol, isopropyl alcohol and ether while polyesters are soluble in dimethylformamide, dimethyl sulfoxide and ethyl acetate. The symbol ++ indicates that the solubility of polyesters to respective solvent, whereas \pm \pm indicates partly soluble and symbol -- indicates that polyester is insoluble in the respective solvent (Table-2). 
RASĀYAN J. Chem.

Vol. 13 | No. 3 |1458-1471| July - September | 2020

Table-2: Relative Solubility of Polyesters

\section{Viscosity}

\begin{tabular}{|c|c|c|c|c|c|c|c|c|c|c|}
\hline Solvent & $\underset{Z}{\prime}$ & $\mathcal{Z}_{Z}^{\prime}$ & $\stackrel{n}{Z}$ & $\begin{array}{l}\forall \\
Z \\
Z\end{array}$ & $\begin{array}{l}n \\
\text { Zn }\end{array}$ & $\begin{array}{l}0 \\
1 \\
Z \\
Z\end{array}$ & $\tilde{U}^{\prime}$ & $\begin{array}{l}\infty \\
\vdots \\
Z\end{array}$ & $\underbrace{a}_{z}$ & $\frac{0}{U^{\prime}}$ \\
\hline DMF & ++ & ++ & ++ & ++ & ++ & ++ & ++ & ++ & ++ & ++ \\
\hline DMSO & ++ & ++ & ++ & ++ & ++ & ++ & ++ & ++ & ++ & ++ \\
\hline Chloroform & - & - & - & - & - & - & - & - & - & -- \\
\hline $\mathrm{CCl}_{4}$ & -- & - & -- & - & -- & - & - & -- & - & - \\
\hline Acetone & \pm \pm & \pm \pm & \pm \pm & \pm \pm & \pm \pm & \pm \pm & \pm \pm & \pm \pm & \pm \pm & \pm \pm \\
\hline Benzene & - & - & - & - & - & - & - & - & - & - \\
\hline Chlorobenzene & - & - & - & - & - & - & - & - & - & -- \\
\hline Methanol & \pm \pm & \pm \pm & \pm \pm & \pm \pm & \pm \pm & \pm \pm & \pm \pm & \pm \pm & \pm \pm & \pm \pm \\
\hline Ethanol & \pm \pm & \pm \pm & \pm \pm & \pm \pm & \pm \pm & \pm \pm & \pm \pm & \pm \pm & \pm \pm & \pm \pm \\
\hline THF & \pm \pm & \pm \pm & \pm \pm & \pm \pm & \pm \pm & \pm \pm & \pm \pm & \pm \pm & \pm \pm & \pm \pm \\
\hline n-Butanol & \pm \pm & \pm \pm & \pm \pm & \pm \pm & \pm \pm & \pm \pm & \pm \pm & \pm \pm & \pm \pm & \pm \pm \\
\hline IPA & \pm \pm & \pm \pm & \pm \pm & \pm \pm & \pm \pm & \pm \pm & \pm \pm & \pm \pm & \pm \pm & \pm \pm \\
\hline Ether & \pm \pm & \pm \pm & \pm \pm & \pm \pm & \pm \pm & \pm \pm & \pm \pm & \pm \pm & \pm \pm & \pm \pm \\
\hline Ethyl acetate & ++ & ++ & ++ & ++ & ++ & ++ & ++ & ++ & ++ & ++ \\
\hline
\end{tabular}

Intrinsic, reduced and inherent viscosity for all the polyesters at various concentrations were determined at $25 \pm 0.1^{\circ} \mathrm{C}$. The relative ( $\eta \mathrm{rel}$ ) and specific ( $\left.\eta \mathrm{sp}\right)$ viscosities, reduced and inherent viscosities were calculated from experimental data. Typical Huggins and Kraemer plots were used to obtain intrinsic viscosity for polyesters. Intrinsic, reduced and inherent viscosities along with Huggin's and Kraemer's constants for $1 \%$ solution are shown in Table-3.

Table-3: Viscosity Values and Huggins's (K') and Kraemer's Constants (K').

\begin{tabular}{c|c|c|c|c|c}
\hline Polyester & {$[\eta]$} & $\eta_{\text {sp }} / \mathrm{C}$ & $\ln \eta_{\text {rel }} / \mathrm{C}$ & $\mathrm{K}^{\prime}$ & $\mathrm{K}^{\prime \prime}$ \\
\hline NC-1 & 0.800 & 0.982 & 0.684 & 0.284 & 0.171 \\
\hline NC-2 & 0.722 & 0.852 & 0.616 & 0.254 & 0.200 \\
\hline NC-3 & 0.653 & 0.772 & 0.572 & 0.279 & 0.190 \\
\hline NC-4 & 0.651 & 0.760 & 0.565 & 0.257 & 0.203 \\
\hline NC-5 & 0.480 & 0.558 & 0.443 & 0.339 & 0.160 \\
\hline NC-6 & 0.493 & 0.571 & 0.451 & 0.320 & 0.172 \\
\hline NC-7 & 0.431 & 0.490 & 0.398 & 0.318 & 0.178 \\
\hline NC-8 & 0.462 & 0.511 & 0.412 & 0.230 & 0.234 \\
\hline NC-9 & 0.382 & 0.430 & 0.357 & 0.331 & 0.172 \\
\hline NC-10 & 0.432 & 0.492 & 0.400 & 0.322 & 0.172 \\
\hline
\end{tabular}

The observations of intrinsic viscosities of Polyesters [NC] reveal that NC-1 which contains Bisphenol-A as diol has the highest solution viscosity, whereas NC-9 has the lowest intrinsic viscosity which contains aliphatic Mono Ethylene Glycol. The range of inherent viscosity is $0.357-0.684 \mathrm{~g} / \mathrm{dl}$. The intrinsic viscosity of the polyesters obtained from coumarin and $\mathrm{N}$-phenyl anthranilic acid follows the sequence given below:

$$
\text { NC-9 }<\text { NC-7 }<\text { NC-10 < NC-8 }<\text { NC-5 }<\text { NC- } 6<\text { NC-4 }<\text { NC-3 }<\text { NC- }<\text { NC-1 }
$$

Typical Huggins's and Kraemer's plots were used to obtain intrinsic viscosity for each of polyesters [NC]. Intrinsic, reduced and inherent viscosities along with Huggin's and Kraemer's constants for 1\% solution are shown in Figs.-1, 2 and 3.

\section{IR spectra}

IR spectra of polyester NC-4 (Fig.-4)revealed C-N stretching vibration at $1269 \mathrm{~cm}^{-1},>\mathrm{C}=\mathrm{O}$ stretching vibration at $1665 \mathrm{~cm}^{-1}$, Ar-O-Ar sym. at $1179 \mathrm{~cm}^{-1}$ and $\mathrm{Ar}-\mathrm{O}-\mathrm{Ar}$ asymmetric at 1136 . Out of plane vibration of s-triazine ring at $824.49 \mathrm{~cm}^{-1}$, in-plane vibration of s- triazine at $1485 \mathrm{~cm}^{-1}, \mathrm{C}=\mathrm{O}$ stretching vibration of $-\mathrm{COOR}$ group at $1772 \mathrm{~cm}^{-1}, \mathrm{C}-\mathrm{H}$ stretching vibration of $\mathrm{CH}_{3}$ at $2923 \mathrm{~cm}^{-1}$. 
RASĀYAN J. Chem.

Vol. 13 | No. 3 |1458-1471| July - September | 2020

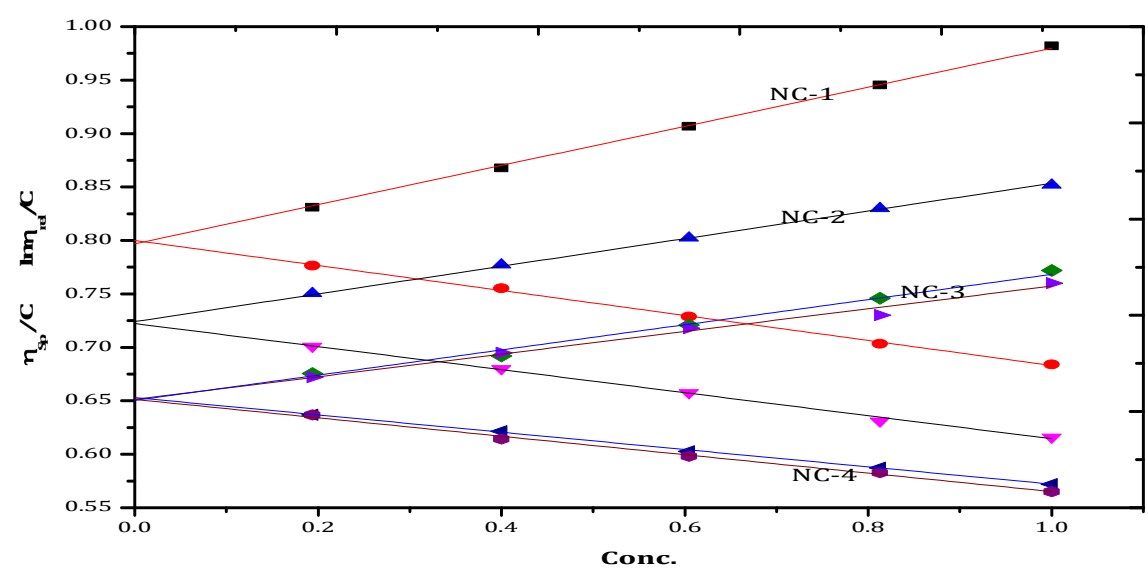

Fig.-1: Typical Huggins's and Kraemer's Plots for NC-1, NC-2, NC-3, NC-2

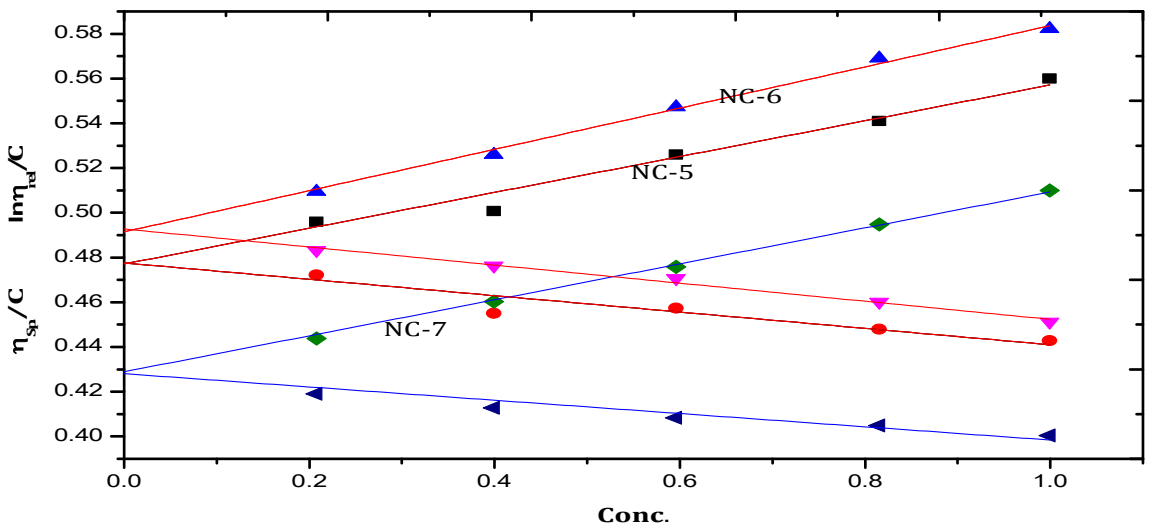

Fig.-2: Typical Huggins's and Kraemer's Plots for NC-5, NC-6, NC-7

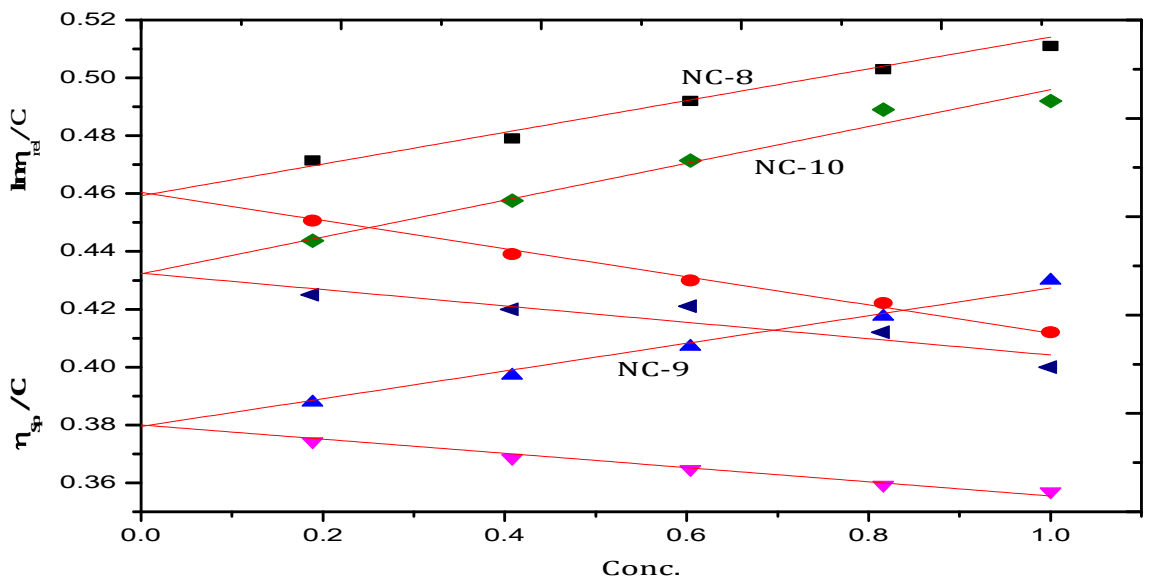

Fig.-3: Typical Huggins's and Kraemer's Plots for NC-8, NC-9, NC-10

IR spectra of polyester NC-10 (Fig.-5)revealed C-N stretching vibration at $1274 \mathrm{~cm}^{-1},>\mathrm{C}=\mathrm{O}$ stretching vibration at $1665 \mathrm{~cm}^{-1}, \mathrm{Ar}-\mathrm{O}-\mathrm{Ar}$ sym. at 1158 and $\mathrm{Ar}-\mathrm{O}-\mathrm{Ar}$ asymmetric at $1135 \mathrm{~cm}^{-1}$. Out of plane vibration of s-triazine ring at $839 \mathrm{~cm}^{-1}$, in-plane vibration of s- triazine at $1488 \mathrm{~cm}^{-1}, \mathrm{C}=\mathrm{O}$ stretching vibration of COOR group at $1770 \mathrm{~cm}^{-1}, \mathrm{C}-\mathrm{H}$ stretching vibration of $\mathrm{CH}_{3}$ at $2922 \mathrm{~cm}^{-1}$. IR spectra of all polyesters are described in Table-4. 
RASĀYAN J. Chem.

Vol. 13 | No. 3 |1458-1471| July - September | 2020

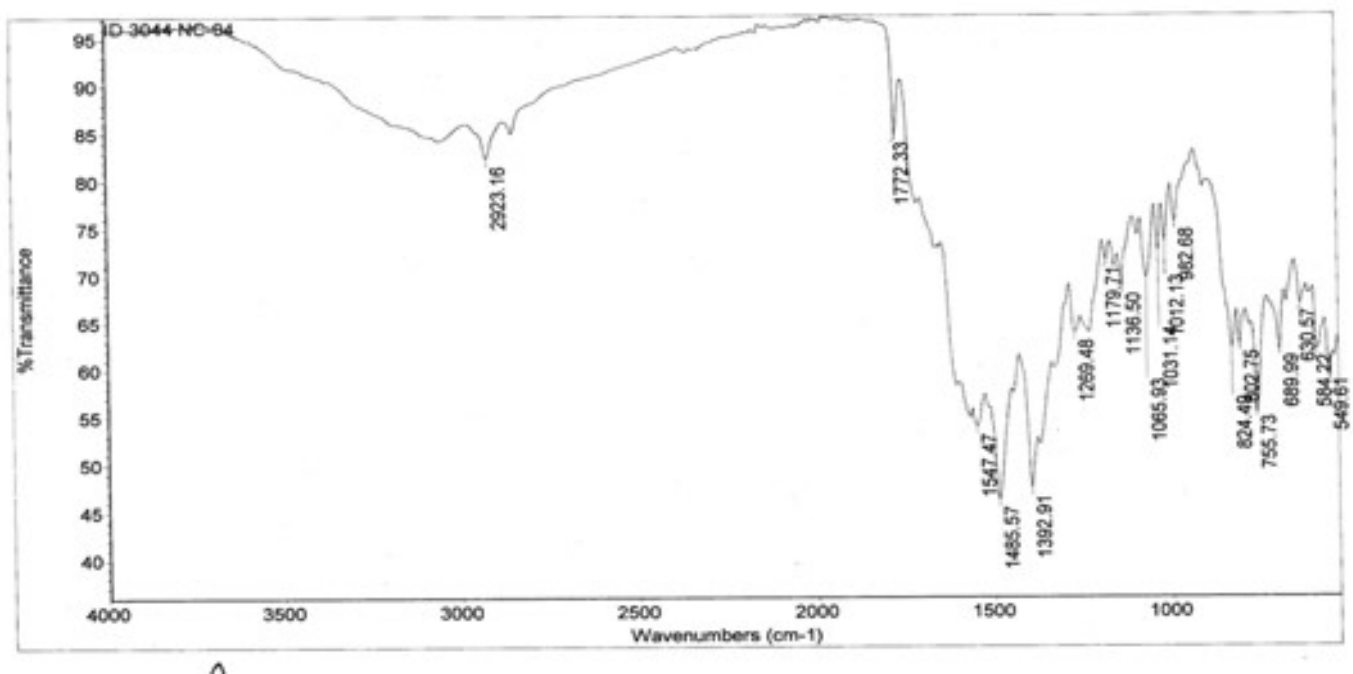

Fig.-4: IR Spectra of NC-4

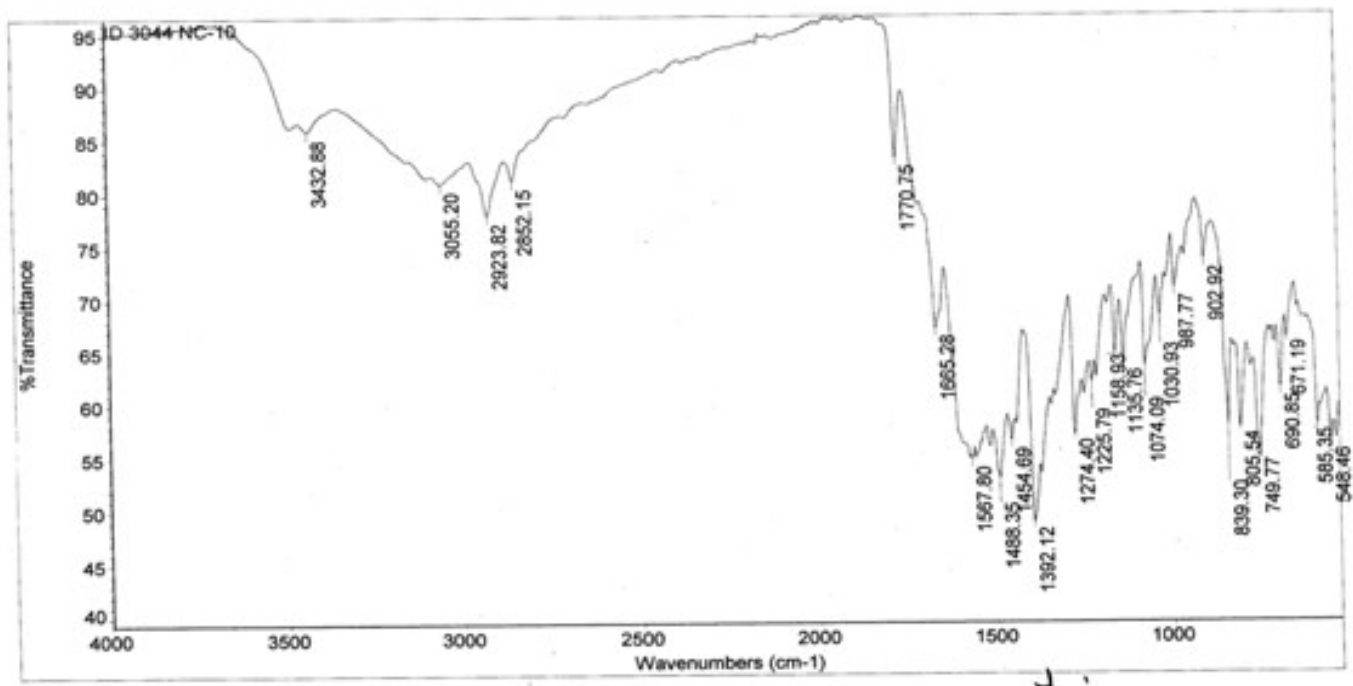

Fig.-5: IR Spectra of NC-10

Table-4: IR Absorption Frequencies of NC Polyesters

\begin{tabular}{|c|c|c|c|c|c|c|c|}
\hline \multirow{2}{*}{$\begin{array}{c}\text { Polyester } \\
\left(\mathrm{cm}^{-1}\right)\end{array}$} & \multirow{2}{*}{$\begin{array}{c}>\mathrm{C}-\mathrm{N} \\
\text { Stretching }\end{array}$} & \multirow{2}{*}{$\begin{array}{c}>\mathrm{C}=\mathrm{O} \\
\text { Coumarine }\end{array}$} & \multicolumn{2}{|c|}{ Ar-O-Ar } & \multicolumn{2}{|c|}{ s-triazine } & \multirow{2}{*}{$\begin{array}{l}>\mathrm{C}=\mathrm{O} \\
-\mathrm{COOR}\end{array}$} \\
\hline & & & (sym) & (asym) & Out Plane & In Plane & \\
\hline NC-1 & 1225 & 1664 & 1175 & 1134 & 824 & 1486 & 1769 \\
\hline $\mathrm{NC}-2$ & 1282 & 1676 & 1174 & 1140 & 833 & 1482 & 1770 \\
\hline NC-3 & 1226 & 1672 & 1160 & 1142 & 822 & 1484 & 1772 \\
\hline NC-5 & 1232 & 1670 & 1171 & 1144 & 823 & 1484 & 1770 \\
\hline NC-6 & 1229 & 1670 & 1165 & 1137 & 824 & 1484 & 1772 \\
\hline $\mathrm{NC}-7$ & 1226 & 1665 & 1158 & 1135 & 824 & 1482 & 1768 \\
\hline NC-8 & 1225 & 1666 & 1159 & 1136 & 840 & 1491 & 1772 \\
\hline NC-9 & 1225 & 1665 & 1158 & 1135 & 839 & 1488 & 1771 \\
\hline
\end{tabular}

\section{${ }^{1}$ H NMR Spectra}

${ }^{1} \mathrm{H}$ NMR spectra of polyester NC-1(Fig.-6), the multiple signals of aromatic protons appear at 6.62-8.94 $\delta$, the singlet at $1.54 \delta$ proves the presence of $\mathrm{CH}_{3-}$ group of Bisphenol- $\mathrm{A}$ and the singlet at $1.24 \delta$ indicates the presence of $-\mathrm{CH}_{3}$ - a group of coumarin, the singlet at 3.37 proves the presence of $-\mathrm{CH}_{2}-$ group. 
RASĀYAN J. Chem.

Vol. 13 | No. 3 |1458-1471| July - September | 2020

${ }^{1} \mathrm{H}$ NMR spectra of polyester NC-4 (Fig.-7), the multiple signals of aromatic protons appear at 6.12-7.78 $\delta$, the singlet at $3.38 \delta$ proves the ester linkage with Neo-Pentyl glycol and the singlet at $1.21 \delta$ indicates the presence of- $\mathrm{CH}_{3}$ a group of coumarin, the singlet at 3.38 proves the presence of $-\mathrm{CH}_{2}-$ group. ${ }^{1} \mathrm{H}$ NMR spectra of all polyesters are described in Table- 5 .

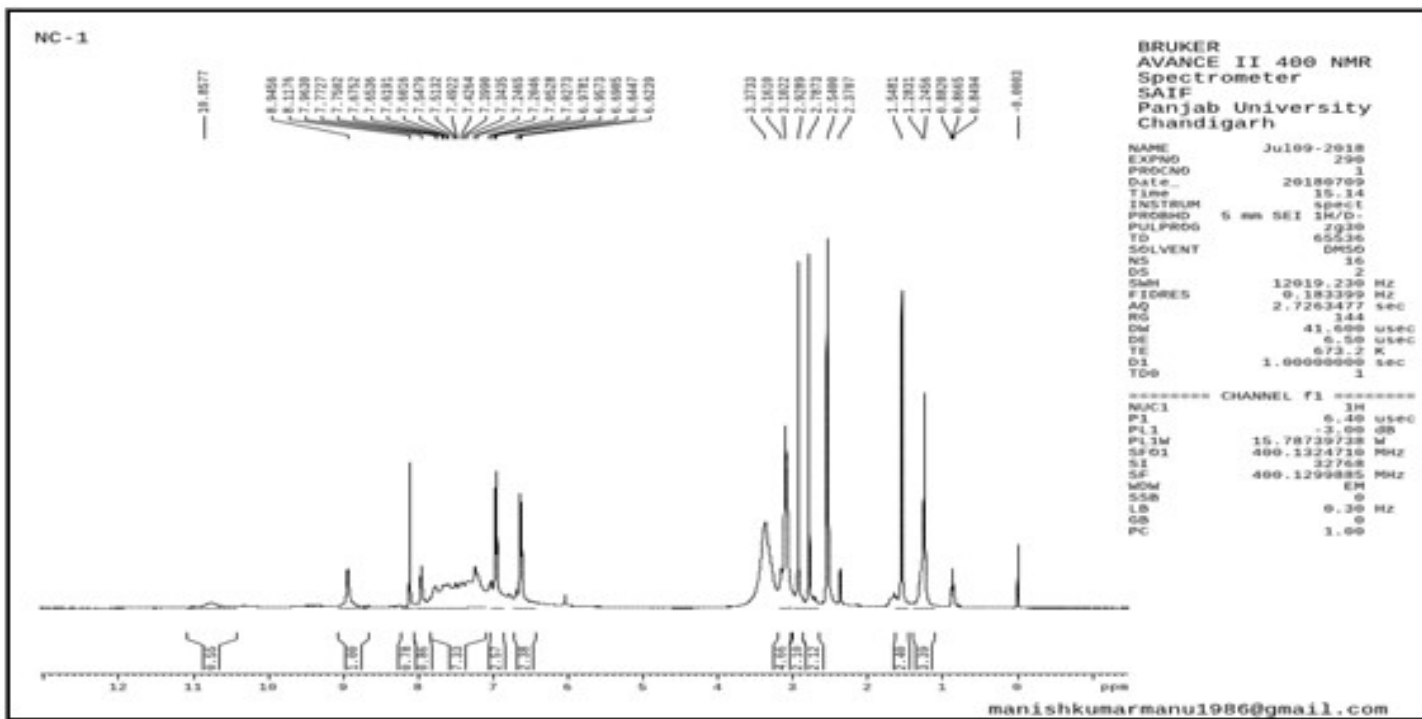

Fig.-6: ${ }^{1} \mathrm{H}$ NMR Spectra of Polyester NC-1

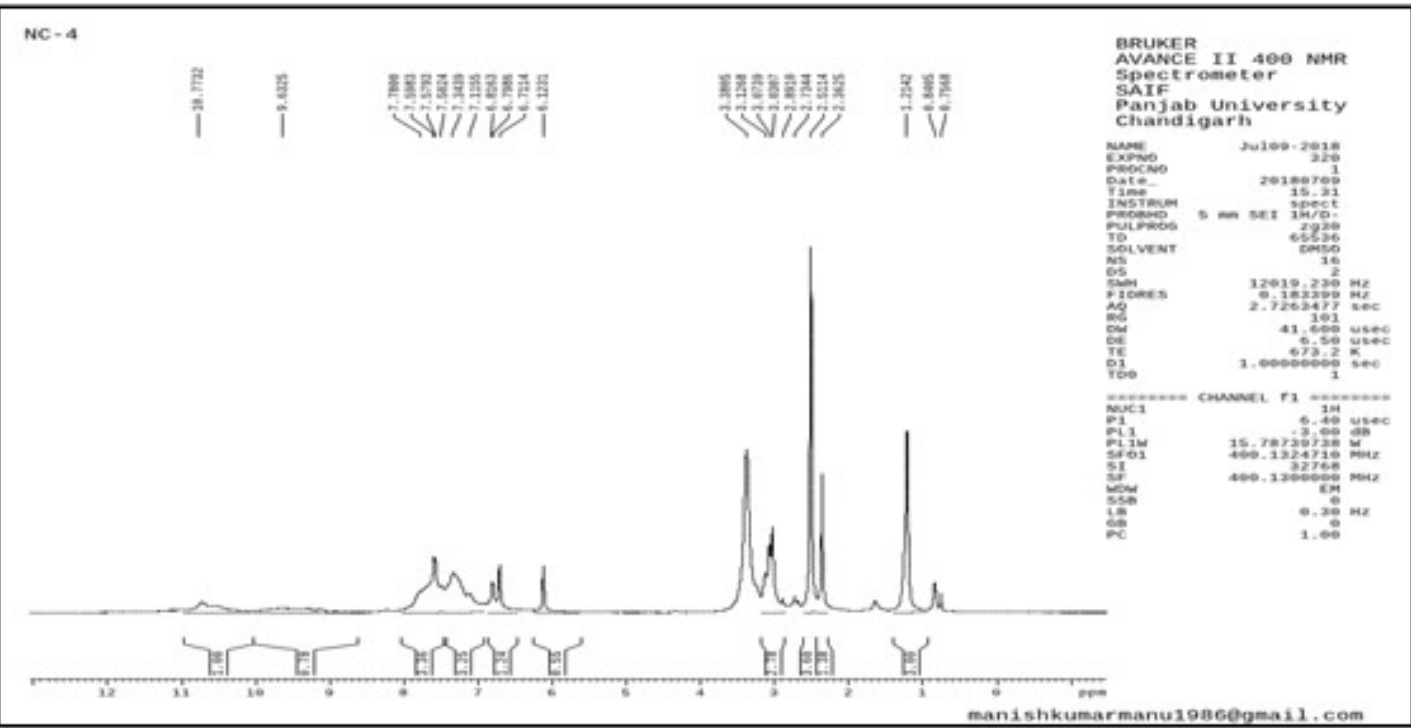

Fig.-7: ${ }^{1} \mathrm{H}$ NMR Spectra of Polyester NC-4

Table-5: ${ }^{1} \mathrm{H}$ NMR Chemical Shift of Polyesters [NC]

\begin{tabular}{c|c|c|c}
\hline \multirow{2}{*}{ Polyester } & \multicolumn{3}{|c}{ Chemical Shift $(\delta \mathrm{ppm})$} \\
\cline { 2 - 4 } & Ar-H Protons (m) & $\begin{array}{c}>\mathrm{CH}_{3}-\text { Group } \\
\text { (s) Coumarin }\end{array}$ & $-\mathrm{CH}_{2}-$ Group (s) \\
\hline NC-2 & $6.89-7.71$ & 1.23 & 3.41 \\
\hline NC-3 & $6.15-7.65$ & 1.20 & 3.38 \\
\hline NC-4 & $6.12-7.78$ & 1.21 & 3.38 \\
\hline NC-5 & $6.11-7.15$ & 1.20 & 3.39 \\
\hline NC-6 & $6.10-7.57$ & 1.18 & 3.42 \\
\hline
\end{tabular}


RASĀYAN J. Chem.

Vol. 13 | No. 3 |1458-1471| July - September | 2020

\begin{tabular}{c|c|c|c}
\hline NC-7 & $6.13-7.72$ & 1.23 & 3.41 \\
\hline NC-8 & $6.14-7.75$ & 1.21 & 3.40 \\
\hline NC-9 & $6.11-7.78$ & 1.20 & 3.38 \\
\hline NC-10 & $6.87-7.71$ & 1.21 & 3.40 \\
\hline
\end{tabular}

\section{Thermogravimetric Analysis}

The TGA data were used to establish the initial degradation temperature, degradation rate, residual weight at the end of degradation, and degradation kinetic parameters. The weight loss of polyesters during thermal degradation is a function of degradation rate and degradation time. At a higher heating rate, although the degradation rate was higher, the time to reach a given temperature became shorter and the residual weight at a given temperature during thermal degradation may be higher. The remaining solid residue after complete pyrolysis was char and ash. TGA was used to determine the thermal degradation characteristics and kinetic parameters. An attempt is made to assess the thermal stability of some of the polyesters qualitatively based on visual obtained thermograms. $T_{0}$ and $T_{10}$ are some of the main criteria of the thermal stability of the polyesters. The higher the $\mathrm{T}_{0}$ and $\mathrm{T}_{10}$, the higher will be the heat stability of polyesters. TGA curve obtains at a scan rate of $10^{\circ} \mathrm{C} / \mathrm{min}$ for polyesters.

The thermal properties of the NC-1 were examined by TGA at a heating rate of $100^{\circ} \mathrm{C} / \mathrm{min}$ under a nitrogen atmosphere. The $10 \%$ weight loss temperature of the aromatic polyester in nitrogen was recorded at 277 ${ }^{\circ} \mathrm{C}$. The $50 \%$ weight loss temperature of the aromatic polyester in nitrogen was recorded at $567^{\circ} \mathrm{C}$.

The thermal properties of the NC-5 were examined by TGA at a heating rate of $100^{\circ} \mathrm{C} / \mathrm{min}$ under a nitrogen atmosphere. The $10 \%$ weight loss temperature of the aromatic polyester in nitrogen was recorded at 266 ${ }^{\circ} \mathrm{C}$. The $50 \%$ weight loss temperature of the aromatic polyester in nitrogen was recorded at $576{ }^{\circ} \mathrm{C}$.

TGA thermograms of NC-1 and NC-5 polyesters are shown in Figs.-8 and 9 respectively which exhibited high thermal stability.

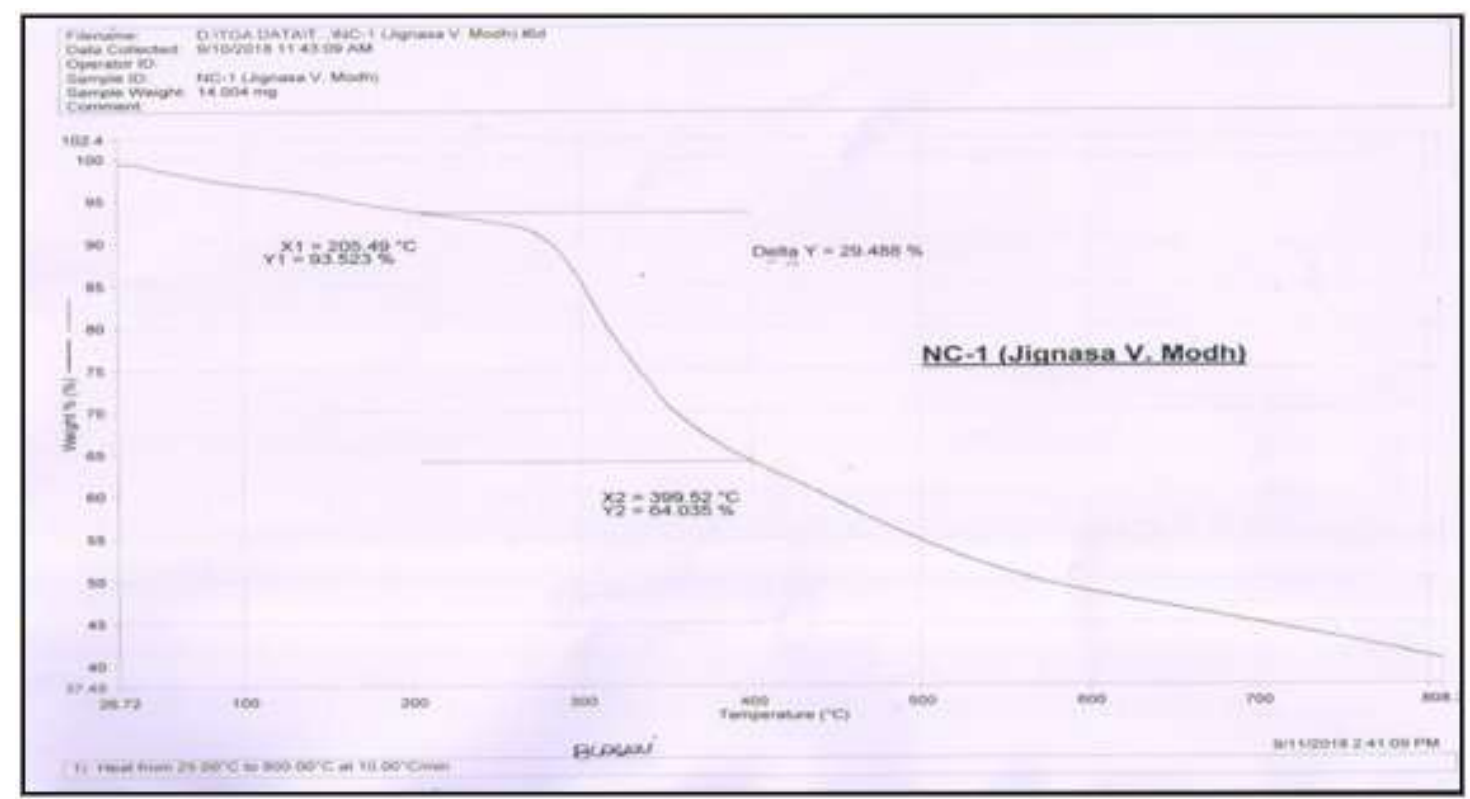

Fig.-8: TGA Thermograms of NC-1

Thermal characteristics of NC-1 and NC-5 are described in Tables- 6,7,8,9 and 10.

Table-6: Thermal Characteristics of Polyesters NC-1 and NC-5.

\begin{tabular}{c|c|c|c|c|c}
\hline \multirow{2}{*}{ Polymer } & \multirow{2}{*}{$\mathrm{T}_{0}\left({ }^{\circ} \mathrm{C}\right)$} & \multirow{2}{*}{$\mathrm{T}_{10}\left({ }^{\circ} \mathrm{C}\right)$} & \multicolumn{2}{|c|}{$\mathrm{T}_{\max }$} & \multirow{2}{*}{$\mathrm{T}_{\mathrm{s}}{ }^{\circ} \mathrm{C}$} \\
\cline { 4 - 5 } & & & Step-1 & Step-2 & \\
\hline NC-1 & 157.04 & 277.04 & 317.04 & 507.04 & 417.04 \\
\hline NC-5 & 146.49 & 266.49 & 316.49 & 516.49 & 416.49 \\
\hline
\end{tabular}


RASĀYAN J. Chem.

Vol. 13 | No. 3 |1458-1471| July - September | 2020

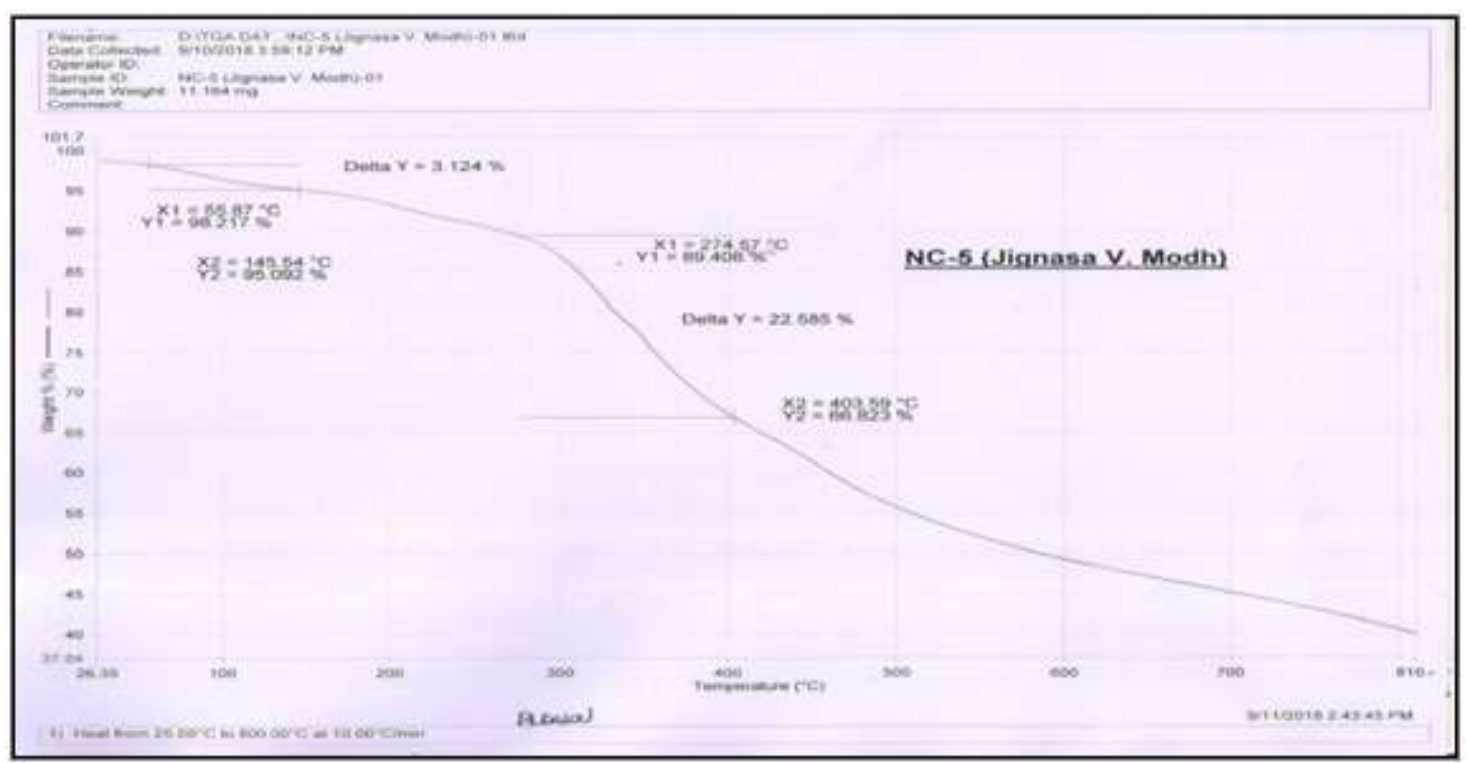

Fig.-9: TGA Thermograms of NC-5

Table-7: Broido Method of Polyesters NC-1.

\begin{tabular}{c|c|c|c|c|c|c}
\hline $\begin{array}{c}\mathrm{T} \\
{ }^{\circ} \mathrm{C}\end{array}$ & $\% \mathrm{Wt}$ & $\begin{array}{c}\mathrm{Y}=\mathrm{Wt}-\mathrm{W} \infty / \mathrm{W} 0- \\
\mathrm{W} \infty\end{array}$ & $1 / \mathrm{Y}$ & $\begin{array}{c}\ln \ln \\
{[1 / \mathrm{Y}]}\end{array}$ & $\begin{array}{c}\mathrm{T} \\
{ }^{\circ} \mathrm{K}\end{array}$ & $\begin{array}{c}1000 / \mathrm{T}\left(\mathrm{K}^{-}\right. \\
1)\end{array}$ \\
\hline 290 & 86.07 & 0.7745 & 1.2911 & -1.3645 & 563 & 1.7761 \\
\hline 300 & 82.88 & 0.7195 & 1.3898 & -1.1112 & 573 & 1.7452 \\
\hline 310 & 79.46 & 0.6615 & 1.5117 & -0.8837 & 583 & 1.7152 \\
\hline 320 & 76.71 & 0.6148 & 1.6265 & -0.7206 & 593 & 1.6863 \\
\hline 330 & 74.15 & 0.5713 & 1.7503 & -0.5801 & 603 & 1.6583 \\
\hline 340 & 71.40 & 0.5246 & 1.9062 & -0.4383 & 613 & 1.6312 \\
\hline 350 & 69.43 & 0.4912 & 2.0358 & -0.3412 & 623 & 1.6051 \\
\hline
\end{tabular}

Table-8: Horowitz- Metzger Method of Polyester NC-1.

\begin{tabular}{c|c|c|c|c|c}
\hline $\mathrm{T}^{\circ} \mathrm{C}$ & $\% \mathrm{Wt}$ & $1-\alpha$ & $1 / 1-\alpha$ & $\ln \ln [1 / 1-\alpha]$ & $\theta^{\circ} \mathrm{K}$ \\
\hline 290 & 86.07 & 0.7745 & 1.2911 & -1.3645 & -30 \\
\hline 300 & 82.88 & 0.7195 & 1.3898 & -1.1112 & -20 \\
\hline 310 & 79.46 & 0.6615 & 1.5117 & -0.8837 & -10 \\
\hline 320 & 76.71 & 0.6148 & 1.6265 & -0.7206 & 0 \\
\hline 330 & 74.15 & 0.5713 & 1.7503 & -0.5801 & 10 \\
\hline 340 & 71.40 & 0.5246 & 1.9062 & -0.4383 & 20 \\
\hline 350 & 69.43 & 0.4912 & 2.0358 & -0.3412 & 30 \\
\hline
\end{tabular}

Table-9: Broido Method of Polyesters NC-5.

\begin{tabular}{c|c|c|c|c|c|c}
\hline $\mathrm{T}^{\circ} \mathrm{C}$ & $\% \mathrm{Wt}$ & $\begin{array}{c}\mathrm{Y}=\mathrm{Wt}-\mathrm{W} \infty \\
\mathrm{W} 0-\mathrm{W} \infty\end{array}$ & $1 / \mathrm{Y}$ & $\ln \ln [1 / \mathrm{Y}]$ & $\mathrm{T}^{\circ} \mathrm{K}$ & $1000 / \mathrm{T}\left(\mathrm{K}^{-1}\right)$ \\
\hline 280 & 88.47 & 0.8240 & 1.2135 & -1.6424 & 553 & 1.8083 \\
\hline 290 & 87.33 & 0.8046 & 1.2428 & -1.5261 & 563 & 1.7761 \\
\hline 300 & 85.74 & 0.7775 & 1.2861 & -1.3798 & 573 & 1.7452 \\
\hline 310 & 83.72 & 0.7430 & 1.3458 & -1.2140 & 583 & 1.7152 \\
\hline 320 & 81.44 & 0.7041 & 1.4202 & -1.0475 & 593 & 1.6863 \\
\hline 330 & 79.17 & 0.6654 & 1.5028 & -0.8981 & 603 & 1.6583 \\
\hline 340 & 77.35 & 0.6342 & 1.5767 & -0.7867 & 613 & 1.6312 \\
\hline
\end{tabular}


RASĀYAN J. Chem.

Vol. 13 | No. 3 |1458-1471| July - September | 2020

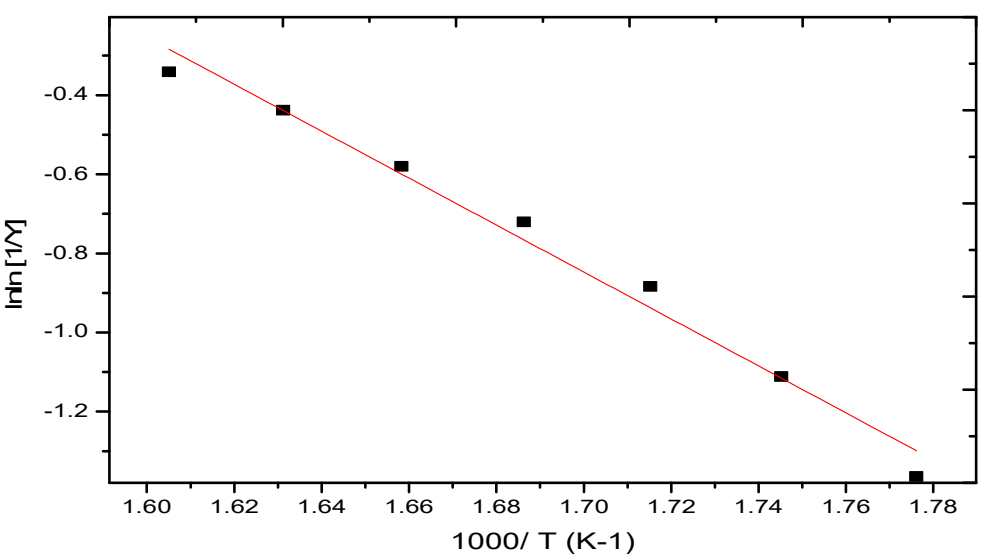

Fig.-10: Broido Plot for NC-1

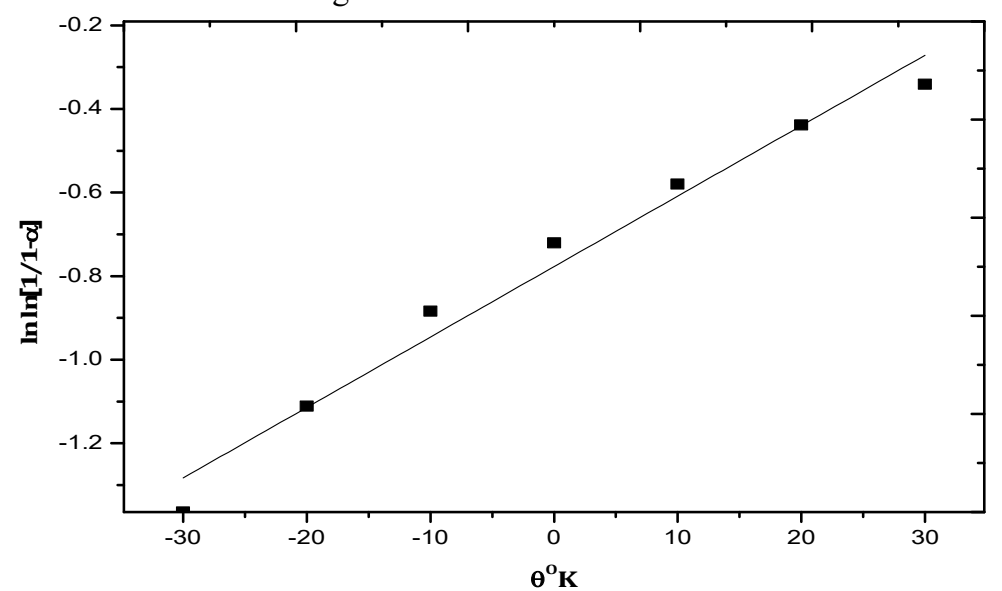

Fig.-11: Horowitz- Metzger Plot for NC-1.

Table-10: Horowitz- Metzger Method of Polyester NC-5.

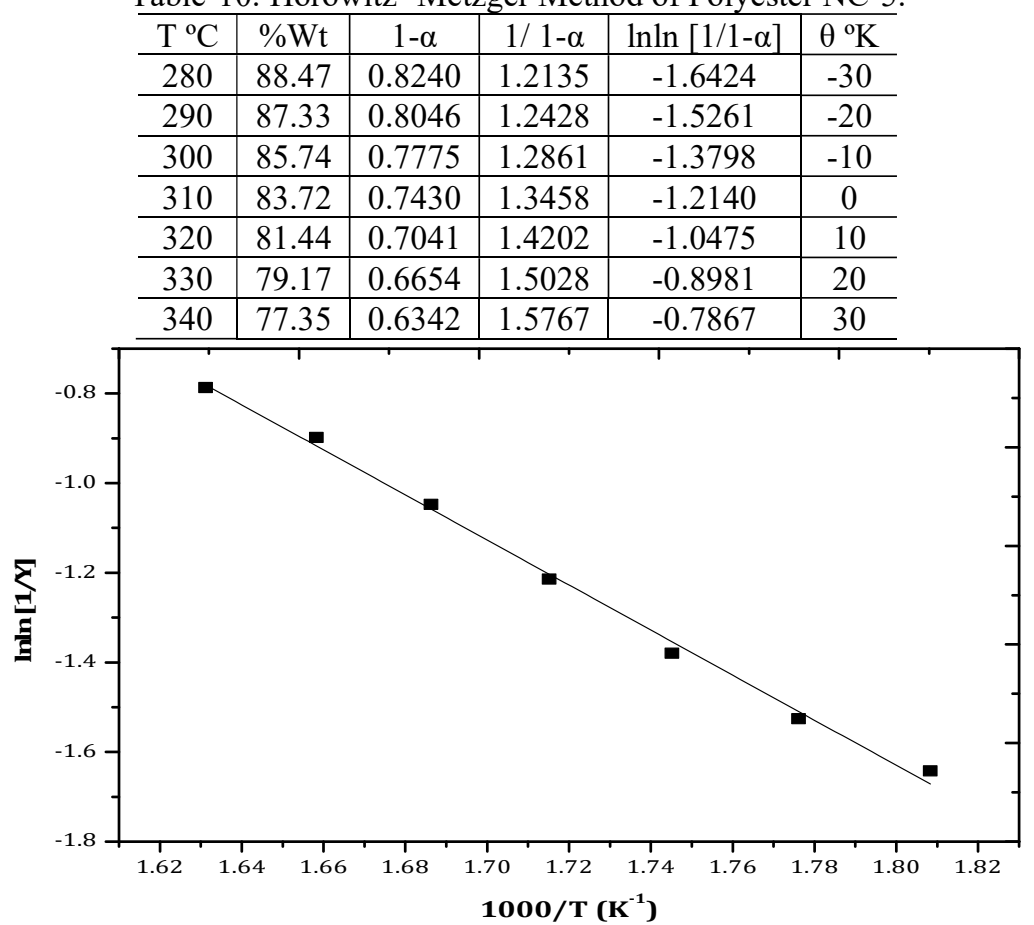

Fig.-12: Broido Plot for NC-5 
RASĀYAN J. Chem.

Vol. 13 | No. 3 |1458-1471| July - September | 2020

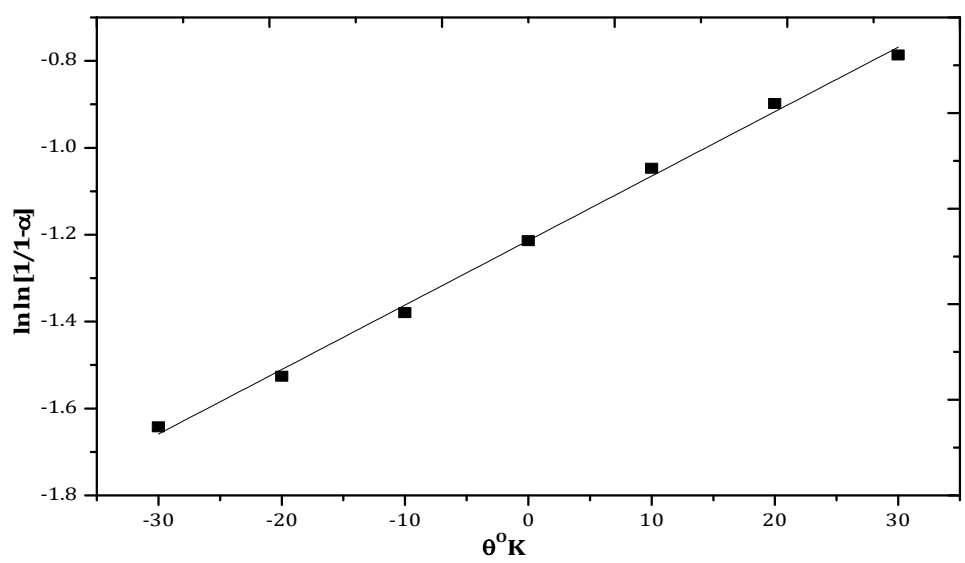

Fig.-13: Horowitz- Metzger Plot for NC-5

Linear deterioration analysis of the experimental data gives the straight lines. The values of apparent activation energy corresponding to degradation steps involved are evaluated from the data and are presented in Table. An examination of the energy of activation E in Table-11 reveals that both the methods yield analogous value for $\mathrm{E}$.

Table-11: Activation Energy From Broido and Horowitz and Metzger Method.

\begin{tabular}{c|c|c|c}
\hline \multirow{2}{*}{ Polymer Code } & Broido & \multicolumn{2}{c}{ Horowitz- Metzger } \\
\cline { 2 - 4 } & $\mathrm{Ea}(\mathrm{K} . \mathrm{Cal} / \mathrm{mol})$ & Ts & Ea $(\mathrm{K} . \mathrm{Cal} / \mathrm{mol})$ \\
\hline $\mathrm{NC}-1$ & 11.78 & 613 & 11.94 \\
\hline $\mathrm{NC}-5$ & 9.97 & 608 & 10.28 \\
\hline
\end{tabular}

Broido method is expected to provide comparatively consistent estimates of $\mathrm{E}$ than Horowitz-Metzger's method as no other temperature characteristics are involved. Activation energy Ea value for $\mathrm{NC}-1$ and $\mathrm{NC}-$ 5 are 11.78 and 11.96, respectively, which are calculated by Broido method. Activation energy Ea value for NC-1 and NC-5 are 9.97 and 10.28, respectively, which are calculated by Horowitz \& Metzger method.

\section{Fluorescence Spectra}

The fluorescence spectrum of the polyesters NC-1 which is synthesized from 7 -Hydroxy 4- Methyl Coumarin, N-phenyl anthranilic acid and Bisphenol - A as an aromatic diol and the polyester NC-6 which is synthesized from 7 -Hydroxy 4- Methyl Coumarin, $\mathrm{N}$-phenyl anthranilic acid and 1,6 Haxene Diol as an aliphatic diol are shown in Figs.-14 and 15.

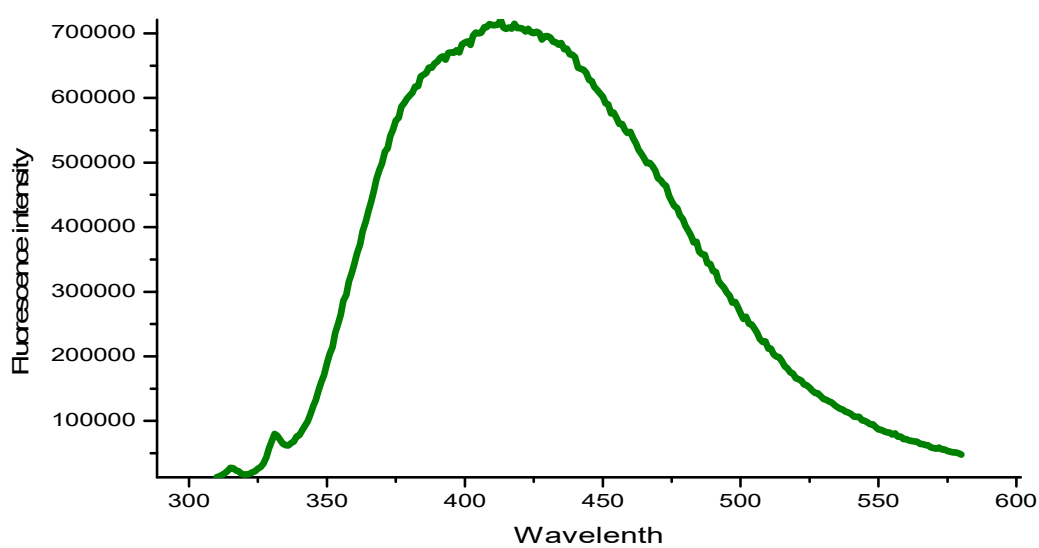

Fig.-14: Fluorescence Spectrum of NC-1.

Polyester NC-1 and NC-6 were dissolved in DMSO- $\mathrm{D}_{6}$ and then excited at $310 \mathrm{~nm}$. Emission spectra were recorded between 250 and $800 \mathrm{~nm}$. Upon excitation at $250 \mathrm{~nm}$, the fluorescence spectrum of NC-1 and NC- 
RASĀYAN J. Chem.

Vol. 13 | No. 3 |1458-1471| July - September | 2020

6 indicates a broaden emission range between 290- $600 \mathrm{~nm}$. The emission peak of NC-1 at $425 \mathrm{~nm}$ and an emission peak of NC-6 at $400 \mathrm{~nm}$. The fluorescence intensity of NC-6 is higher than NC-1. The diminishing of fluorescence intensity does not follow the first-order kinetics model. One can suggest that at least two processes are responsible for the decrease of fluorescence: (1) concentration of fluorescent decreases due to photo cyclization reaction, and (2) fluorescence photo quenching operates in this system via the intermolecular mechanism of energy transfer in photo stationary state.

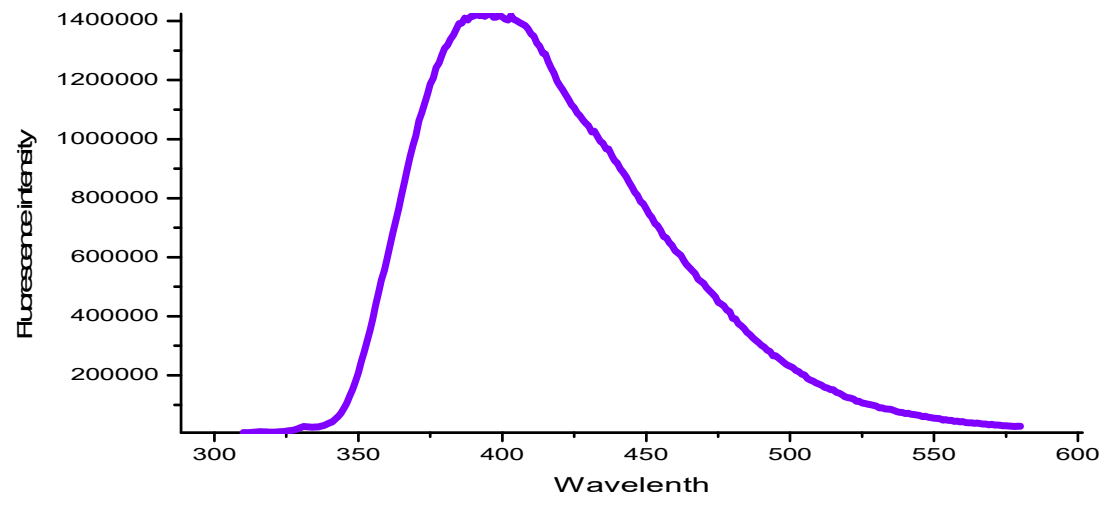

Fig.-15: Fluorescence Spectrum of NC-6.

\section{CONCLUSION}

Newer polyester having an s-triazine ring with $\mathrm{N}$-phenyl anthranilic acid and 7- hydroxy 4 methyl coumarin linkage in the main chain was successfully synthesized by high-temperature polycondensation. The resulting polyesters show outstanding colors and good thermal stability. All the polyesters have poor solubility in halogenated and non-polar solvents, but soluble in dimethylformamide, dimethyl sulfoxide, tetrahydrofuran and ethyl acetate. All the synthesized polyesters show excellent fluorescence which can be used in fluorescent probe, advanced bioimaging, ultrasensitive molecular diagnosis, novel light-emitting nanodevices, chemosensors, biological imaging and drug delivery.

\section{ACKNOWLEDGMENT}

I wish to express my great admiration to the Veer Narmad South Gujarat University, Surat for providing necessary experimental facilities, I am heartily thankful to Dr. (Mrs.) Saurabh K. Patel, Department of Chemistry, V.N.S.G. University, Surat for the best guidance in my research work. I likewise express my gratitude to CSMCRI Bhavnagar; SAIF, Chandigarh, Punjab and A green enviro LTD, center of excellence, Vapi for investigation of the samples.

\section{REFERENCES}

1. K. Wang, W. Huang, P. Xia, C. Gao, D. Yan, Reactive \& Functional Polymers, 52, 143(2002), DOI: 10.1016/S1381-5148(02)00088-3

2. J. Lin, Y. Yuki, H. Kunisada, S. Kondo, Applied Polymer Science, 40, 2113(1990), DOI: 10.1002/app.1990.070401124

3. K. Saida, M. Sakai, T. Narahara, Japan Patent (Jpn Kokai Tokkoya Koho), 52, 136(1977)

4. C.P.R. Nair, K.N. Ninan, Polymers \& Polymer Composites, 12(1), 55(2004), DOI: 10.1177/096739110401200105

5. H. Sheng, F. Zhao, X. Yu, K. Naito, X. Qu, Q. Zhang, High Performance Polymer, 1(2015), DOI: $10.1177 / 0954008315591192$

6. P. May, Polymer electronics. Phys. World, 8, 52(1995)

7. H. Nakada, T. Tohma, Inorganic and Organic Electroluminescence; (Wissenschaft-und- Technik: Berlin), Germany, 385(1996)

8. A.O. Patil, A.J. Heeger, F. Wudl, Chemical Reviews, 88(1), 183(1988), DOI: 10.1021/cr00083a009 
RASĀYAN J. Chem.

Vol. 13 | No. 3 |1458-1471| July - September | 2020

9. J.H. Burroughes, D.D.C. Bradley, A.R. Brown, R.N. Marks, K. Mackay, R.H. Friend, P.L.Burns, A.B. Holmes, Nature, 347, 539(1990)

10. D. Bradley, Current Opinion in Solid State \& Material Science, 1, 789(1996)

11. A.C. Show, H.J. Tzu, H.L. Hsin, Journal of the Chinese Chemical Society, 57, 439(2010)

12. K.C. Fox, New Science, 141, 3(1994)

13. D.R. Baigent, N.C. Greenham, J. Grüner, R.N. Marks, R.H. Friend, S.C. Moratti, A.B. Holmes, Synthetic Metals, 67, 3(1994)

14. P. Yam, Scientific American, 273, 74(1995)

15. M. Tasior, Y.M. Poronik, O. Vakuliuk, B. Sadowski, M. Karczewski, D.T. Gryko, The Journal of Organic Chemistry, 79(18), 8723(2014), DOI: 10.1021/jo501565r

16. C. Yu, Y. Wu, F. Zeng, X. Li, J. Shi, S. Wu, Biomacromolecules, 14(12), 4507(2013), DOI: $10.1021 / \mathrm{bm} 401548 \mathrm{u}$

17. M.A. Halim, Nanomaterials, 3, 22(2013), DOI: 10.3390/nano3010022

18. J. Donovalová, M. Cigáň, H. Stankovičová, J. Gašpar, M. Danko A. Gáplovský, P. Hrdlovič, Molecules, 17, 3259(2012), DOI: 10.3390/molecules17033259

19. L.H. Zhang, T. Jian, L.B. Wan, Chemistry-An Asian Journal, 7, 1583(2012), DOI: 10.1002/asia.201200070

20. W.Y. Li, J.G. Xu, X.W. He, Analytical Letters, 33(15), 3183(2000), DOI: 10.1080/00032719.2000.10399494

21. I. Soutar, L. Swanson, F.G. Thorpe, C. Zhu, Macromolecules, 29(3), 918(1996), DOI: $10.1021 / \mathrm{ma} 9508717$

22. J.R. Lakowicz, Plenum Press, New York, (1999).

23. J.S. Yang, T.M. Swager, American Chemical Society, 120(21), 5321(1998), DOI: 10.1021/ja9742996

24. M.A. Winnik, S.M. Bystryak, Z. Liu, Macromolecules, 31(20), 6855(1998), DOI: 10.1021/ma980672y

25. D. V. Vasava, S. K. Patel, International Letters of Chemistry, Physics and Astronomy, 70, 48 (2016)

26. K. Wang, W. Huang, P. Xia, C. Gao, D. Yan, Reactive \& Functional Polymers, 52(3), 143(2002), DOI: $10.1016 / \mathrm{S} 1381-5148(02) 00088-3$

27. A. Solankee, R. Patel, K. Patel, Der Pharma Chemica, 3 (6), 317(2011)

28. S.G. Sanadhya, S. L. Oswal and K.C. Parmar, Journal of Chemical and Pharmaceutical Research, 6(4), 705(2014)

29. Y.T. Chern and C.M. Huang, Polymer, 39(11), 2325(1998), DOI:10.1016/S0032-3861(97)00519-3

30. P. Ambrosanioa, R. Centorea, S. Concilioa, B. Panunzib, A. Sirigua, N. Tirelli, Polymer, 40, 4923(1999), DOI: 10.1016/S0032-3861(98)00720-4

[RJC-5683/2020] 